American Journal of Economics and Business Administration 3 (1): 219-223, 2011

ISSN 1945-5488

(C) 2010 Science Publications

\title{
A Review Note of KMICe 2010: Knowledge Management Initiatives to Improve Organization Performance
}

\author{
Wan Hussain Wan Ishak \\ Department of Computer Science, College of Arts and Science, \\ University Utara Malaysia, 06010 Sintok, Malaysia
}

\begin{abstract}
Problem statement: Knowledge Management (KM) has been a practice in many organizations to improve its performance towards reaching the organization goals. Realizing its importance, University Utara Malaysia has organized a series of KM conference called KMICe that focus on the recent and novel research findings related to KM. This special issue covers articles that were presented at KMICe 2010. Conclusion: This special issue features articles that are focusing on KM in business organization, KM tools, IT solution that support KM, KM related methodology, KM in academic organization and E-learning. Through these articles knowledge sharing and knowledge transfer are believe to be the most prevailing issues of KM.
\end{abstract}

Key words: KMICe, knowledge management, organization performance

\section{INTRODUCTION}

Knowledge Management (KM) is a well known term that was popularized since 1970s (Wiig, 1997). $\mathrm{KM}$ comprises a range of strategies and practices that can be used by individual and organization to identify, create, represent, distribute and adopt knowledge. According to Wiig (1997), due to economic reality knowledge has become a differentiating competitive factor for individuals, corporations and nations. Knowledge of an individual will drives to an action that can be used to solve a specific problem. Knowledge rich individual is known as Knowledge Worker (Serrat, 2008). In an organization, knowledge can be regarded as an intellectual capital that driven the success of the organization and an important asset to any nation. It has become a valuable resource that allows the nation to function intelligently.

The rapid development of Information Technology (IT) has enable knowledge to be generated and maintain systematically. IT enables organizations to develop and design information systems specifically to facilitate the sharing and integration of knowledge. These systems are referred to as Knowledge Management System (KMS) (Alavi and Leidner, 1999).

Realizing its importance, Universiti Utara Malaysia has organized Knowledge Management International Conference (KMICe). Universiti Utara Malaysia is one of the public universities in Malaysia specializing in management studies. KMICe was organized in series begin with the first KMICe in 2001. The second KMICe was organized in 2004, the third in 2006 and the fourth in 2008.
KMICe serve as a platform for knowledge sharing and discussion of research findings and recent advances in $\mathrm{KM}$ among local and international participants. In general KMICe invites papers from wide range of research areas including knowledge management strategy, knowledge sharing and transfer, data sharing and transfer, the measurement and impact of knowledge management, tools and technology for knowledge management, the process of managing knowledge management project, e-learning, e-training and executive training, organization/corporate memory, a case study on knowledge management, current trends of knowledge management, methodology in knowledge management, content management, performance and operation in knowledge management, the usage of software in corporative environment, intelligent information system, knowledge-based system, decision support system, knowledge management through wireless infrastructure, knowledge workers, issues, challenges and constraints in k-era, the issues of culture variety and cross-culture, k-economy, k-community and k-enterprise, knowledge management theories and practices, quality management and practices and knowledge management principles and tools.

Knowledge management international conference 2010: KMICe 2010 was a fifth of it series since it was first organized in 2001. Since 2001, KMICe has bring together leading researchers and developers in a wide variety of areas, with a common interest in improving the state of the art of KM. KMICe also bring together people from the academia and industry to establish 
closer cooperation and ties and creation of K-based society.

KMICe 2010 was held on May 25-27, 2010 at Kuala Terengganu, Malaysia. The theme of the conference is "Knowledge Management: Theory, Research and Practice". This conference has gathered participants from various countries including Malaysia, Canada, China, South Africa, Iran, India, Australia, Philippine and Nepal. A total of 118 papers have been presented covering a wide range of areas such as economy, education, management, communication and information technology.

Papers for this special issue: The American Journal of Economics and Business Administration (AJEBA) is an academic journal that covers articles related to business and economics. Both business and economic are the field which can get benefits from KM initiatives. In particular, many studies focus directly on how KM can improve the business organization performance and gain the maximum benefit through the rapid growth of the economy regardless of the size of the organization (Abdul-Ghani and Subhan, 2011; Okyere-Kwakye and Nor, 2011; Tan, 2011).

KM in business and organization: Local and international corporation for example can work together through KM initiatives particularly, knowledge sharing that related to business and technology. Abdul-Ghani and Subhan (2011) investigate the possible knowledge sharing between Malaysian and international biotechnology corporations typically European and US firms. The investigation was based on Malaysian managing directors' views. Malaysian firms are willing to provide knowledge on the local economy, politics and policies, while international firms are expected to transfer their technology and knowledge workers.

A smaller size of businesses such as Small and Medium Enterprise (SME) KM can also gain benefit through proper utilization of KM initiatives. Tan (2011) shows that KM success factors investigated in her study has impact on the knowledge management process (knowledge creation, knowledge transfer, knowledge sharing and knowledge utilisation) among SMEs in Malaysia. The success factors observed in this study are culture, leadership, employee participation, Information and Communications Technology (ICT) and organisational structure.

The success of the business organization also influenced by the knowledge sharing among individuals in that organization. Proper and systematic knowledge sharing in an organization can create a prospers environment by which every individuals are working together for the wealth and success of the organization. However, Okyere-Kwakye and Nor (2011) found that individuals in the organization are still reluctant to participate in knowledge management efforts especially knowledge sharing. Okyere-Kwakye and Nor investigates the issue and proposed a conceptual framework which suggests that individual factors: altruism, self efficacy, mutual reciprocity and trust are to have an impact on knowledge sharing initiative.

In the consumer perspective, KM can be utilized to measure consumer's intention to buy or use a product offered by the businesses. Example of this application can be seen from Yee and San (2011). Yee and San (2011) emphasis that in business, consumer's prior knowledge on the product should not be neglected as this knowledge can lead to the purchase decision. Focusing on automobile business, Yee and San (2011) found that consumer buying decision may influenced by the quality, value and risk that they perceived.

KM tools: ITs have been found to be one of the prevailing factors that help to improve the $\mathrm{KM}$ initiatives. IT can be used as a tool to store, manage, manipulate and distribute knowledge either within or outside organization. Jamaludin and Ishak (2011) developed a tool called Virtual Repository (ViRepo) that can be used for departmental information sharing. Jamaludin and Ishak urge that academician in academic organization are keen to participate in information sharing application. They own huge collections of materials which can be shared with other people in the same department. However, sharing and accessing information about these materials is very difficult. The proposed tool, ViRepo allows others to browse every educator's collections. ViRepo proved that the model, in actual fact, allows information access, information sharing, information management, partnership enhancement and allows an utmost repository control by each and every participating educator. The authors believe that the shared information can reduce the cost of findings the academic materials which are important for research and education. Additionally, the proposed information sharing framework can promote team work, teaching and research collaboration.

Another tool that was developed for education purposes is called Student's Mobile Information Prototype (SMIP). This prototype was developed by Alzaza and Yaakub (2011b) based on the user requirements which were identified in Alzaza and Yaakub (2011a). SMIP was proposed to support and facilitate both teachers and learners in M-learning environment. M-learning environment is the education environment that utilizing mobile technologies. The findings shows that users are openly accept the new prototype for the ease of learning. Though the limitations (as highlighted in Alzaza and Yaakub, 
Am. J. of Economics and Business Administration 3 (1): 219-223, 2011

2011a); transaction cost, network speed (for data exchange) and confidentiality of personal information are yet to be resolved.

IT Solution to support KM: In addition to the KM tools develop based on IT platform, IT itself covers wide range of fundamental research that can be used to improve existing KM application. Data storage, retrieving and sharing in a databases and networked environment for example are fundamental aspect in Information and Communication Technology (ICT) that support KM application in an organization.

In the organization, data are usually stored in large database. This databases also called Data Warehouse. Abdul-Aziz et al. (2011) concern with the quality of data stored in Data Warehouses. The quality of data is important for organization to make the best decision over its planning for growth and wealthness. In consequent to the data quality, mining the data from this large database is another important issue. Data mining is a part of knowledge discovery process which was not only to retrieve information from the database but also to ensure that data retrieve are meaningful. Tohidi and Ibrahim (2011) present a problem of frequent pattern mining which is one of problem in data mining research. Realizing the important of this data in decision making and the limitation of existing method, Tohidi and Ibrahim, investigate a new algorithm called Prime Factor Miner (PFM). In their experiment, it was proven that the algorithm has successfully generate frequent pattern with reduce time and memory complexity.

Problems in data sharing also prevailing in most of KM applications especially those that are connected through the network. Studies by Elfaki et al. (2011) and Latip et al. (2011) offers solution to some of the problems. According to Elfaki et al. (2011) technique called cooperative caching is a potential technique to improve the data access performance and availability in mobile ad hoc networks. However, due to technological limitation and client's mobility cache management faces many challenges. To overcome the limitation, they proposed Cluster Cache Collaborative (CCC) technique to reduce the bottleneck in the cache management. Latip et al. (2011) proposed a new protocol called Clustered-based Data Sharing (CDS) to overcome data sharing problem in grid environment. The simulation program develop in this study has prove that the proposed protocol has improve the accessibility of the data. When dealing with a sensitive data, Kuang et al. (2011) offers the solution. The solution proposed by Kuang et al. reduces redundancy and conflict in data sharing.
KM related methodology: Promoting the KM initiatives is not limited to the direct application of KM in organization. In software development process, a methodology called Agile was prove to has influence on knowledge sharing among software development team (Omar et al., 2011). Omar et al. (2011) found that Agile's framework can increase positive affectivity amongst team members during software development projects. This methodology promotes collaborative work that can build knowledge sharing among team members. Knowledge sharing in software development project can promote effective and creative solutions.

Method for dissemination and sharing of knowledge is also another important issue in $\mathrm{KM}$ initiatives. The advancement of Internet and the increase of its user has creates an opportunity for the organization to use website to disseminate information to the potential client. However, the website needs to be regularly maintained to ensure that the website contains accurate and updated information. A study by Mohd Isa et al. (2011) investigates the usability and accessibility of Malaysia e-government websites. The websites was categorized into two categories: state and federal websites. The study shows that state website are having high number of usability and accessibility problems upon comparing to federal website. The authors proposed that e-government website should be regularly maintained and updated. Additionally, egovernment website should be convenient to be used by all range of citizens especially those with disabilities.

In conjunction to the rapid use and abundance of information made available on the Internet, information searching has become a major issue. According to MatYamin and Ramayah (2011) Internet users need to be equipped with knowledge: both knowledge on topic and system in order to satisfy with the searching. Findings of their study, confirm that both types of knowledge are equally significant to support user search satisfaction.

Thye (2011) concern with the quality of the research framework. He investigates Deming's Perspective of research quality by which divided research into two frameworks: enumerative and analytic study. The author commented that analytic study helps to generate new knowledge, rather than enumerative study which provides passive "information”.

KM in academic organization. Academic organization is rich with knowledge as this type of organization deals directly with knowledge creation and knowledge transfer. New knowledge is created through research and development (RandD) activities. The outcome of the research such as product can be commercialized for profit and society benefit. However, information about the research process, constraint and methodology were not being commercialized. Commercialization in this 
aspect was not necessarily mean for profit but rather for dissemination of research knowledge. Yaacob et al. (2011) looking into the commercialization of academia research output through publication of the research outcome in the area of biotechnology. This initiative encourages the sharing of the research outcome which will then create a network of collaboration among researchers in the same field. This study reveals that the experiences related to research and administration and the job status influence the perception on the commercialization initiatives.

Knowledge sharing among academics was studied by Jahani et al. (2011). Knowledge sharing in academic institution is very crucial as "knowledge" is a core of an academic institution. However, knowledge sharing was limited due to certain limitation. Jahani et al. (2011) investigate two key factors that encouraging knowledge sharing in academic institution. The two key factors are intrinsic reward and leadership style. The study was conducted among academician in Iran. The findings confirm that both key factors have influence on the knowledge sharing behavior in the university.

E-Learning: E-learning is one of the important $\mathrm{KM}$ application areas. E-learning is an alternative to traditional classroom learning which utilized ICT to support teaching and learning. Omidinia et al. (2011) conducted a review on E-Learning and ICT Infrastructure in developing countries. The case study was conducted in Iran. Factors that hindered the success of e-learning projects was identified: process focus, implementation expertise, technology focus, open-source technology and one-time funding.

E-learning application can be online or offline mode depends on the aim and the coverage of the application. Typically, if the application is to cover students in a distributed location, online mode is the most preferred. Website is a medium for online elearning that utilizing the Internet technologies. To ensure efficacy of the e-learning website, the quality of the website need to be maintained. This effort can be achieved through the active role of the website developer (Abdellatief et al., 2011). Therefore, Abdellatief et al. (2011) propose a technique to evaluate e-learning website quality from developer's view.

Other examples of e-learning applications are presented by Bahrudin et al. (2011) and Aziz et al. (2011). Bahrudin et al. (2011) develop an interactive courseware for learning basic computer system components. The courseware is called iC-COM. The courseware was used in the classroom in conjunction to the traditional method. Another courseware developed by Aziz et al. (2011) was intended for visually impaired students. Theoretically, the courseware will act as a medium to transfer information to the students.

\section{CONCLUSION}

KM was known to be of one of the important initiatives to improve organization performance. Through the articles presented at KMICe 2010 and published in this special issue, knowledge sharing and knowledge transfer are the most prevailing issues of KM. In addition, IT was shown to be an important tool to support KM. The articles published in this special issue also covers the fundamental aspect of IT research that either directly or indirectly support the KM processes.

\section{ACKNOWLEDGEMENT}

On behalf of KMICe 2010, I would like to thank Science Publications for their invitation and cooperation of publishing this special issue.

\section{REFERENCES}

Abdellatief, M., A.B.M. Sultan, M.A. Jabar and R. Abdullah, 2011. A technique for quality evaluation of e-learning from developers perspective. Am. J. Econ. Bus. Admin., 3: 157-164. DOI: 10.3844/ajebasp.2011.157.164

Abdul-Aziz, A.A., M.Y.M. Saman and M.P. Hamzah, 2011. Using metadata analysis and base analysis techniques in data qualities framework for data warehouses. Am. J. Econ. Bus. Admin., 3: 112119. DOI: 10.3844/ajebasp.2011.112.119

Abdul-Ghani, A.B.A. and M. Subhan, 2011. Biotechnology international strategic alliances: The managerial perspectives of Malaysian firms. Am. J. Econ. Bus. Admin., 3: 1-11. DOI: 10.3844/ajebasp.2011.1.11

Alavi, M. and D.E. Leidner, 1999, Knowledge Management Systems: Issues, Challenges, and Benefits, Communi. Associ. Inform. Syst., 1: 2-37.

Alzaza, N.S. and A.R. Yaakub, 2011(a). Students' awareness and requirements of mobile learning services in the higher education environment. Am. J. Econ. Bus. Admin., 3: 95-100. DOI: 10.3844/ajebasp.2011.95.100

Alzaza, N.S. and A.R. Yaakub, 2011a. Student's mobile information prototype for the higher education environment. Am. J. Econ. Bus. Admin., 3: 81-86. DOI: 10.3844/ajebasp.2011.81.86

Aziz, N., N.H.M. Roseli, E.S. Eshak and A.A. Mutalib, 2011. Assistive courseware for the visually impaired based on theory of multiple intelligence and SECI model. Am. J. Econ. Bus. Admin., 3: 150-156. DOI: 10.3844/ajebasp.2011.150.156 
Bahrudin, I.A., M. Muhammad, M.I.A. Nawawi, I.N. Saharudin and H.M. Din et al., 2011. Development of interactive courseware for learning basic computer system components. Am. J. Econ. Bus. Admin., $\quad 3$ : 132-138. DOI: 10.3844/ajebasp.2011.132.138

Elfaki, M.A., H. Ibrahim, A. Mamat and M. Othman, 2011. Collaborative caching architecture for continuous query in mobile database. Am. J. Econ. Bus. Admin., 3: 33-39. DOI: 10.3844/ajebasp.2011.33.39

Jahani, S., T. Ramayah and A.A. Effendi, 2011. Is reward system and leadership important in knowledge sharing among academics? Am. J. Econ. Bus. Admin., 3: 87-94. DOI: 10.3844/ajebasp.2011.87.94

Jamaludin, Z. and W.H.W. Ishak, 2011. A virtual repository approach to departmental information sharing. Am. J. Econ. Bus. Admin., 3: 18-23. DOI: 10.3844/ajebasp.2011.18.23

Kuang, T.P., H. Ibrahim, N.I. Udzir and F. Sidi, 2011. Security extensible access control markup language policy integration based on role-based access control model in healthcare collaborative environments. Am. J. Econ. Bus. Admin., 3: 101111. DOI: 10.3844 /ajebasp.2011.101.111

Latip, R., H. Ibrahim and F.A. Al-Hanandeh, 2011. Scientific data sharing using clustered-based data sharing in grid environment. Am. J. Econ. Bus. Admin., $\quad 3$ : 146-149. DOI: 10.3844/ajebasp.2011.146.149

Mat-Yamin, F. and T. Ramayah, 2011. The impact of user knowledge on web search satisfaction. Am. J. Econ. Bus. Admin., 3: 139-145. DOI: 10.3844/ajebasp.2011.132.138

Mohd Isa, W.A.R.W, M.R. Suhami, N.I. Safie and S.S. Semsudin, 2011. Assessing the usability and accessibility of Malaysia e-government website. Am. J. Econ. Bus. Admin., 3: 40-46. DOI: 10.3844/ajebasp.2011.40.46

Okyere-Kwakye, E. and K.M. Nor, 2011. Individual factors and knowledge sharing. Am. J. Econ. Bus. Admin., $\quad 3$ : 66-72. DOI: 10.3844/ajebasp.2011.66.72
Omar, M., S.L. Syed-Abdullah and A. Yasin, 2011. The impact of agile approach on software engineering teams. Am. J. Econ. Bus. Admin., 3: 12-17. DOI: 10.3844/ajebasp.2011.12.17

Omidinia, S., M. Masrom and H. Selamat, 2011. Review of e-learning and ict infrastructure in developing countries (case study of Iran). Am. J. Econ. Bus. Admin., 3: 120-125. DOI: 10.3844/ajebasp.2011.120.125

Serrat, O. 2008, Managing Knowledge Workers. Knowledge Solutions. http://www.adb.org/Documents/Information/Know ledge-Solutions/Managing-KnowledgeWorkers.pdf

Tan, C.N.L., 2011. Knowledge management acceptance: success factors amongst small and medium-size enterprises. Am. J. Econ. Bus. Admin., $\quad 3: \quad 73-80 . \quad$ DOI: 10.3844/ajebasp.2011.73.80

Thye, K.E., 2011. Quality research framework: Enumerative study versus analytic study from deming's perspective. Am. J. Econ. Bus. Admin., 3: 126-131. DOI: 10.3844/ajebasp.2011.126.131

Tohidi, H. and H. Ibrahim, 2011. Using unique-primefactorization theorem to mine frequent patterns without generating tree. Am. J. Econ. Bus. Admin., 3: 58-65. DOI: 10.3844/ajebasp.2011.58.65

Wiig, K.M., 1997. Knowledge Management: Where did it come from and where will it go? Expert Syst. Appl., 13: 1-14. DOI: 10.1016/S09574174(97)00018-3

Yaacob, N.A., A.M. Rasli, A.A. Senin and S.N. Othman, 2011. Perceptions of commercialization activities of research results among academic researchers in Malaysia. Am. J. Econ. Bus. Admin., 3: 24-32. DOI: 10.3844/ajebasp.2011.24.32

Yee, J. and N.C. San, 2011. Consumers' perceived quality, perceived value and perceived risk towards purchase decision on automobile. Am. J. Econ. Bus. Admin., 3: 47-57. DOI: 10.3844/ajebasp.2011.47.57 